\title{
Doppler Evaluation of Vertebral Artery in Cervical Spondylosis - A Prospective Study in Rural Indian Set Up
}

\author{
Vaishali Dhawan ${ }^{1}$, Bodhraj Dhawan ${ }^{2}$ \\ ${ }^{1}$ Department of Radiodiagnosis, MGIMS, Sevagram, Wardha, Maharashtra, India. \\ ${ }^{2}$ Department of Ophthalmology, NKP Salve Institute of Medical Sciences, Nagpur, Maharashtra, India.
}

\section{ABSTRACT}

\section{BACKGROUND}

So far, evaluation of vertebral arteries has been done by angiography with a limited data on evaluation with duplex scanning of the vertebral arteries. We wanted to study the radiological features and vertebral artery Doppler characteristics, in patients aged above 35 years with a clinical diagnosis of cervical spondylosis.

\section{METHODS}

This is a case control study with a total of 120 subjects aged over 35 years ( 60 subjects were cases with the clinical diagnosis of cervical spondylosis and the remaining 60 subjects were age matched controls). Vertebral artery colour Doppler was performed to record peak systolic velocity, time averaged maximum velocity, diameter of the segment in grey scale in millimetres and flow volume of the vertebral artery. Statistical analysis was done using chi square test, student t test and $\mathrm{z}$ test with $\mathrm{p}$ values $<0.05$ being considered statistically significant.

\section{RESULTS}

Majority of patients in both groups were in the age group 41 - 50 years. Among cases 39 (65\%) were males and 21 (35\%) were females. Most of cases had vertebral artery diameters in the range of $3.0-3.5 \mathrm{~mm}$ seen both on right [21\{35\%\}] as well as on left side [17 $\{28.3 \%\}]$, and a similar finding was observed in controls as well. No statistical significance was observed amongst cases and control on either right or left side. Most of the cases had vertebral artery blood flow in the range of 51-100 $\mathrm{mL} / \mathrm{min}$ both on right side [26 (43.3\%)] and left side [22 (36.7\%). On comparing vertebral artery blood flow in the range of $\leq 100 \mathrm{~mL} / \mathrm{min}$ and $>100 \mathrm{~mL} / \mathrm{min}$, the difference was statistically significant on the left side. On comparing the number of cases and controls according to the vertebral artery blood flow velocity $\leq 30 \mathrm{~cm} / \mathrm{s}$ and $>30 \mathrm{~cm} / \mathrm{sec}$ on right side, p value was 0.009 and that on the left was 0.001 , both of which are statistically significant.

\section{CONCLUSIONS}

Vertebral artery diameter is not a very reliable sign in this degenerative condition. Vertebral artery flow volume is decreased at least in one vertebral artery. Vertebral artery blood flow velocity was significantly reduced in cervical spondylosis cases compared to controls both on right side $(\mathrm{p}=0.009)$ and left side $(\mathrm{p}=0.001)$. This makes reduced vertebral artery blood flow velocity as a very strong sign in this condition. To conclude vertebral artery ultrasound is a very useful and reliable tool in evaluation of vertebrobasilar insufficiency cases.

\section{KEY WORDS}

Vertebral Artery, Colour Doppler Ultrasound, Cervical Spondylosis
Corresponding Author:

Vaishali Dhawan,

\#30, H. B. Estate,

Sonegaon, Nagpur-440025,

Maharashtra, India.

E-mail: bodhrajdhawan@gmail.com

DOI: $10.14260 /$ jemds/2020/525

How to Cite This Article:

Dhawan V, Dhawan B. Doppler evaluation of vertebral artery in cervical spondylosisa prospective study in rural Indian set up. J Evolution Med Dent Sci 2020;9(34):24132416, DOI: 10.14260/jemds/2020/525

Submission 15-04-2020,

Peer Review 14-07-2020,

Acceptance 21-07-2020,

Published 24-08-2020.

Copyright (C) 2020 JEMDS. This is an open access article distributed under Creative Commons Attribution License [Attribution 4.0 International (CC BY 4.0)] 


\section{BACKGROUND}

Degenerative changes of the cervical spine are common in symptomatic and asymptomatic adults, ${ }^{1}$ which lead to malfunction in vertebral artery blood flow affecting brain and vestibulocochlear organ blood flow. ${ }^{2}$ Vascular trauma and resultant atherosclerosis of the vertebral artery has been related to "Cervical vertigo", in which vessels are tortuous with stenotic changes. ${ }^{3}$ So far the evaluation of vertebral arteries has been done by angiography with a limited data on evaluation with duplex scanning of the vertebral arteries, ${ }^{4}$ and the role of duplex ultrasound in identifying the external compression of the vertebral artery has not been extensively studied. ${ }^{5}$ Hence the present study was undertaken to study the radiological features and vertebral artery Doppler characteristics in patients aged above 35 years with clinical diagnosis of cervical spondylosis.

\section{METHODS}

It is a Case Control Study, conducted in Radiological Department of a Tertiary care Teaching institute in Central India, with a total 120 subjects (60 consecutive cases with the clinical diagnosis of Cervical Spondylosis and 60 age matched controls) aged over 35 years, were enrolled by Convenience. Patients with cardiac problems or with otogenic vertigo were excluded. Evaluation was performed on "Logic 500 MD MR 3 Wipro GE Sonography machine" with a linear array transducer of 6-9-megahertz frequency. Imagesoft programme was used for the recording of images.

After taking an informed consent, Clinical history of pain in nape of neck, stiffness and vertigo was noted. The Radiographic evaluation of the cervical spine in standard Anteroposterior, lateral and oblique view was done. These views were evaluated in terms of-

1. Curvature-Presence of Normal Lordosis/Loss of Normal Lordosis/Reversal of Lordosis (Kyphosis) as evaluated on Lateral views.

2. Osteophytes- Presence and Levels of Posterior and anterior osteophytes as evaluated on lateral and oblique views

3. Disc Spaces- the Height and level of reduction of height of intervertebral disc as evaluated on Lateral views.

4. Facet Joints- Narrowing and Fuzziness in the facet joints were looked for.

5. Canal Diameter- Sagittal Canal Diameter was measured on Lateral views (Sagittal Canal Diameter less than 12 mm was considered significant)

Vertebral artery Colour Doppler was performed in supine position with neck hyperextended and rotated to the side opposite being examined, using a $7.0 \mathrm{MHz}$ frequency, following characteristics of the vertebral artery were recorded-

1. Peak systolic Velocity.

2. Time averaged maximum velocity.

3. The Diameter of the Segment in grey scale in millimetres.

4. Flow volume of the vertebral artery.
Statistical analysis was done using Chi square test with $\mathrm{p}$ values $<0.05$ being considered statistically significant.

\section{RESULTS}

\section{Demographic Profile}

A total 60 patients with clinical diagnosis of cervical spondylosis as Cases and another 60 patients as Controls were included. Majority of patients in both groups were in the age group 41-50 years [30 (50\%)] amongst cases and [28 (46.6\%)] amongst controls. Among cases 39 (65\%) were males and 21 (35\%) females. In the control group 30 (50\%) were males and a similar number were females.

\section{Distribution of Cases According to Symptoms}

Most common symptom was Neck Pain in 60 (100\% cases). It was followed by Neck stiffness in 43 (71.6\% cases), Radiating Neck pain 39 (65\%), Neck pain with vertigo in 35 (58.3\%) and Neck pain with Stiffness with Radiation 30 (50\%). Other symptoms included Neck pain with stiffness with vertigo in $25(41.6 \%$, Neck pain with radiation with Vertigo in 23 $(38.3 \%)$ and Neck pain with stiffness with radiation with Vertigo in $19(31.6 \%)$ cases.

\section{Distribution of Patients According to Radiographic Findings}

Main Radiographic Finding amongst cases was Both Posterior and Anterior Osteophytes seen in 40 (66.6\%) cases, followed by Decreased intervertebral Disc Space in 39 (65\%), Loss of Curvature of Cervical spine being observed in 30 (50\%) of the cases. It was followed by Fuzzy articular margins in 20 $(33.3 \%)$ cases. In the controls 22 (36.6\%) had both Posterior and anterior Osteophytes as a prominent finding.

\section{Distribution of Patients According to the Diameter of Vertebral Artery as Seen on Gray Scale Sonography (Figure No. 1)}

Most of Cases had vertebral artery diameters in the range of 3.0-3.5 mm seen both on right $[21\{35 \%\}]$ as well as on left side $[17\{28.3 \%\}]$ and a similar finding was observed in controls as well. No Statistical significance was observed amongst cases and control on either right ( $p$ value 0.084 ) or left side ( $\mathrm{p}$ value 0.28 ).

\section{Distribution of Patients According to the Blood Flow Volume of the Vertebral Arteries (Table No. 1, Figure No. 2)}

Most of the cases had Vertebral artery blood flow in the range of $51-100 \mathrm{~mL} / \mathrm{min}$ both on right side [26 (43.3\%)] and Left side [22 (36.7\%). In the control group, two different groups of patients [26 each (43.3\%)] had Vertebral artery blood flow in the range of $51-100 \mathrm{~cm} / \mathrm{s}$ and $101-150 \mathrm{cms} / \mathrm{s}$ on the right side. On the left side majority of the controls [33 (55\%)] had the Vertebral artery blood flow in the range of $51-100 \mathrm{~cm} / \mathrm{s}$. 
On comparing Vertebral artery blood flow in the range of $\leq 100 \mathrm{~mL} / \mathrm{min}$ and $>100 \mathrm{~mL} / \mathrm{min}$, the difference was statistically significant on the left side ( $p$ value 0.036 ).

\section{Distribution of Patients According to the Blood Flow Velocity of Vertebral Arteries on Doppler Study (Table No. 2, Figure No. 3)}

Among the cases the maximum number of cases showed the vertebral artery blood flow in the range of $31-40 \mathrm{~cm} / \mathrm{s}$ both on right side [24 (40\%)] and on the left side [19 (31.7\%)]. In the control group, majority cases $[25(41.7 \%)$ had a vertebral artery blood flow in the range of $41-50 \mathrm{~cm} / \mathrm{s}$ on the right side. On the left side the majority of controls [34 (56.7\%)] had the vertebral artery blood flow in the range of $31-40 \mathrm{~cm} / \mathrm{s}$. On comparing number of cases and controls according to the vertebral artery blood flow velocity $\leq 30 \mathrm{~cm} / \mathrm{s}$ and $>30$ $\mathrm{cm} / \mathrm{sec}$ on Right side, $\mathrm{p}$ value was 0.009 and that on the left was 0.001 , both of which are statistically significant.

\begin{tabular}{|ccccc|}
\hline $\begin{array}{c}\text { Blood Flow Volume } \\
\text { mL/min }\end{array}$ & \multicolumn{2}{c}{ Cases } & \multicolumn{2}{c|}{ Controls } \\
$<50$ & $4(6.7 \%)$ & $7(11.7 \%)$ & $4(6.7 \%)$ & $1(1.7 \%)$ \\
$51-100$ & $26(43.3 \%)$ & $22(36.7 \%)$ & $26(43.3 \%)$ & $33(55 \%)$ \\
$101-150$ & $18(30 \%)$ & $19(31.7 \%)$ & $26(43.3 \%)$ & $19(31.7 \%)$ \\
$151-200$ & $8(13 \%)$ & $10(16.7 \%)$ & $3(5 \%)$ & $5(8.3 \%)$ \\
$201-250$ & 0 & $1(1.7 \%)$ & $1(1.7 \%)$ & $2(3.3 \%)$ \\
$251-300$ & $2(3.3 \%)$ & 0 & 0 & 0 \\
$301-350$ & $2(3.3 \%)$ & 0 & 0 & 0 \\
Not Visualised & 0 & $1(1.7 \%)$ & 0 & 0 \\
\hline Table 1. Distribution of Patients According to Blood Flow Volume of \\
the Vertebral Arteries in Millilitres per Minute \\
\hline
\end{tabular}

\begin{tabular}{|ccccc|}
\hline $\begin{array}{c}\text { Blood Flow } \\
\text { Velocity cm/s }\end{array}$ & $\begin{array}{c}\text { Right } \\
\mathbf{p}=\mathbf{0 . 0 0 9}\end{array}$ & $\begin{array}{c}\text { Left } \\
\mathbf{p = 0 . 0 0 1}\end{array}$ & Right & Left \\
Less than 10 & 0 & 0 & 0 & 0 \\
$11-20$ & $2(3.3 \%)$ & 0 & 0 & 0 \\
$21-30$ & $12(20 \%)$ & $17(28.3 .3 \%)$ & $4(6.7 \%)$ & $2(3.3 \%)$ \\
$31-40$ & $24(40 \%)$ & $19(31.7 \%)$ & $24(40 \%)$ & $34(56.7 \%)$ \\
$41-50$ & $15(25 \%)$ & $13(31.7 \%)$ & $25(41.7 \%)$ & $20(33.3 \%)$ \\
$51-60$ & $3(5 \%)$ & $7(11.7 \%)$ & $3(5 \%)$ & $2(3.3 \%)$ \\
$61-70$ & $3(5 \%)$ & $3(5 \%)$ & $4(6.7 \%)$ & $2(3.3 \%)$ \\
$71-80$ & $1(1.7 \%)$ & 0 & 0 & 0 \\
Not Visualised & 0 & $1(1.7 \%)$ & 0 & 0 \\
\hline Table 2. Distribution of Patients According to the Blood Flow Velocity \\
\multicolumn{5}{c}{ of Vertebral Arteries on Doppler Study } \\
\hline
\end{tabular}

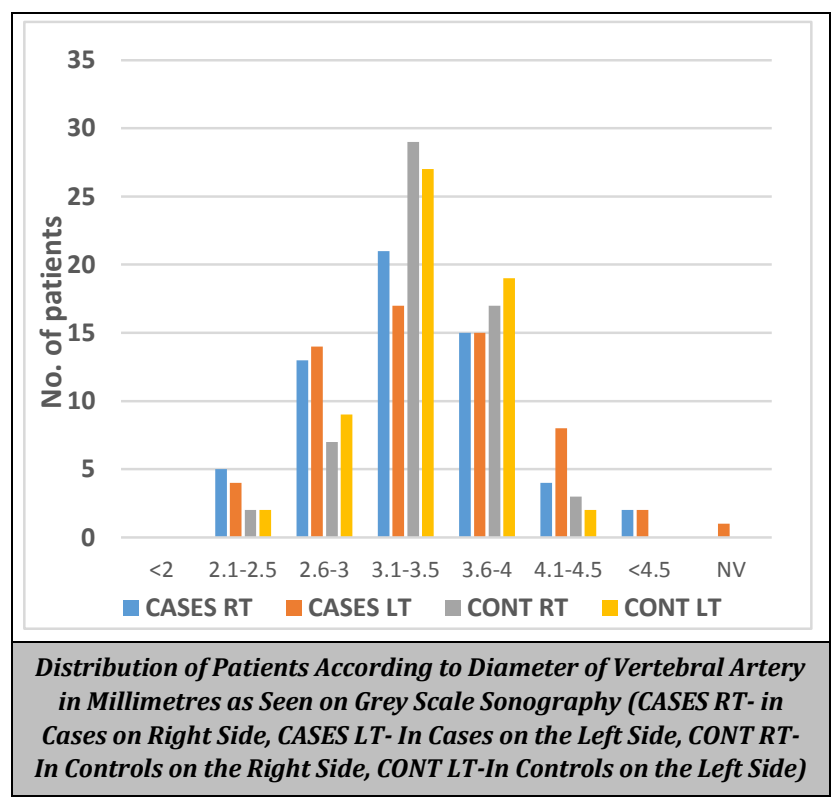

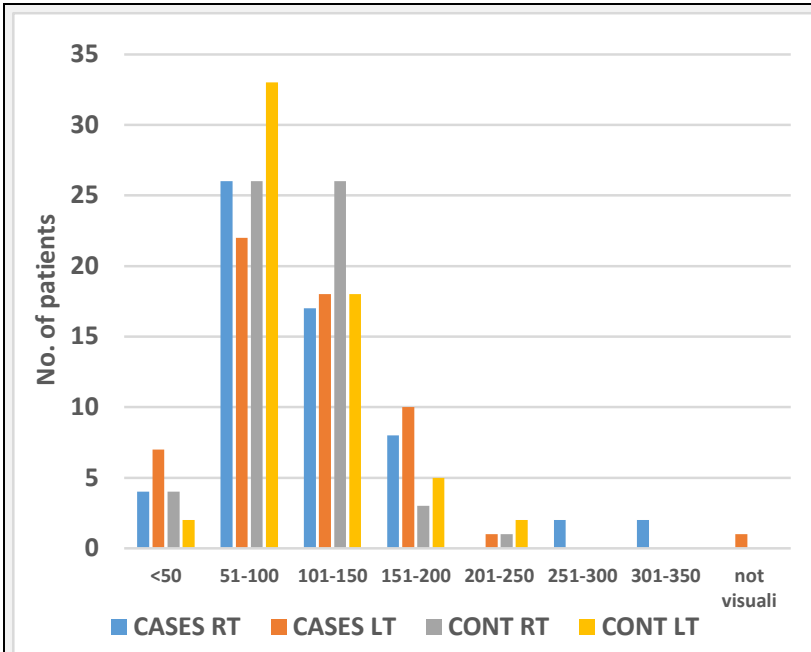

Figure 2. Distribution of Patients According to Blood Flow Volume in Millilitres per Minute of the Vertebral Arteries (CASES RT-In Cases on Right Side, CASES LT-In Cases on the Left Side, CONT RT-In Controls on the Right Side, CONT LT-In Controls on the Left Side)

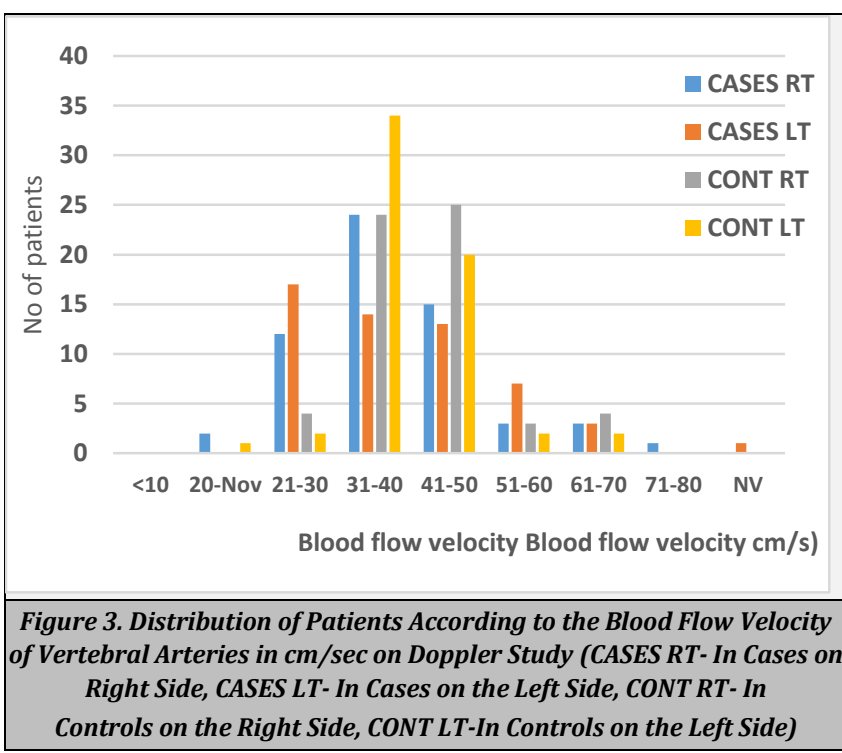

\section{DISCUSSION}

This Study includes 60 patients with the clinical diagnosis of Cervical Spondylosis 60 controls which were compared for Clinical, Radiological and Doppler Characteristics of Vertebral artery. Most commonly encountered age group was 41-50 years and there was male Preponderance with $65 \%$ being males is consistent with the literature report for similar cases. 6,7

Most common symptom was Neck Pain in $60(100 \%$ cases). It was followed by Neck stiffness in 43 (71.6\% cases), Radiating Neck pain 39 (65\%), Neck pain with vertigo in 35 (58.3\%) and Neck pain with Stiffness with Radiation 30 (50\%). This is different from published reports where radiating pain and headache were commonest presenting complaints. ${ }^{7}$

On Observing the Degenerative changes of the cervical spine, point of importance was that one or more features of Degeneration of Spine was seen in $100 \%$ cases. However even in $73 \%$ of controls also such observation was present, 
indicating that one cannot fully rely on Radiography only in these cases. Many published reports support these findings where no significant difference was seen in degenerative changes on radiography between cases and matched controls. 6,8

Most of Cases had vertebral artery diameters in the range of 3.0-3.5 mm seen both on right [21 $\{35 \%\}]$ as well as on left side [17 $\{28.3 \%\}]$ and a similar finding was observed in controls as well. No Statistical significance was observed amongst cases and control on either right or left side.

Hence the present study observes a symmetry between vertebral artery diameters on both sides as reported in the literature. ${ }^{9,10}$

Most of the cases had Vertebral artery blood flow in the range of 51-100 $\mathrm{mL} / \mathrm{min}$ both on right side [26 (43.3\%)] and Left side [22 (36.7\%). No statistically significant difference in the blood flow volumes of the two sides was noted. The present study shows decreased blood flow volume in at least one vertebral artery in cervical spondylosis. This matches with earlier reports by Liu MH et al.11

Among the cases the maximum number of cases showed the vertebral artery blood flow in the range of $31-40 \mathrm{~cm} / \mathrm{s}$. Some other authors have reported vertebral artery mean velocity to be $45.9 \mathrm{~cm} / \mathrm{s}$ on right and $51.5 \mathrm{~cm} / \mathrm{s}$ on the left side. ${ }^{12}$

On comparing number of cases and controls according to the vertebral artery blood flow velocity $<=30 \mathrm{~cm} / \mathrm{s}$ and $>30$ $\mathrm{cms} / \mathrm{sec}$ on Right side, p value was 0.009 and that on the left was 0.001 , both of which are statistically significant. Hence the flow velocity in the vertebral artery is significantly reduced in cases as compared to controls both on right and left side. However, there was no statistically significant difference in the vertebral artery flow velocity between right and left side. Similar results reporting reduction in velocity in vertebrobasal arterial system in degenerative diseases have been reported by Machala et al.13

\section{CONCLUSIONS}

Radiographic features are seen in all cases of cervical spondylosis, but one or more of such features were noted even in $73 \%$ of the controls (asymptomatics), Hence radiographic signs are suggestive but not specific to the symptoms. Vertebral artery diameter was seen to be in the range of $3.1-3.5 \mathrm{~mm}$ in majority of cases and controls; however, there was no statistically significant difference in vertebral artery diameter among cases and controls, indicating that it is not a very reliable sign in this degenerative condition. Vertebral artery flow volume was significantly reduced on the left side when cases were compared with controls $(\mathrm{p}=0.036)$, which means that in patients with cervical spondylosis, the blood flow volume was decreased at least in one vertebral artery. Vertebral artery blood flow velocity was significantly reduced in cervical spondylosis cases compared to controls both on right side $(p=0.009)$ and left side $(p=0.001)$. This makes reduced vertebral artery blood flow velocity a very strong sign in this condition. To conclude vertebral artery ultrasound is a very useful and reliable tool in the evaluation of vertebrobasilar deficiency cases.

Financial or Other Competing Interests: None.

\section{REFERENCES}

[1] Gore DR. Radiological evaluation of degenerative cervical spine. In: The Cervical Spine Research Society Editorial Committee, Ed. The cervical spine. $3^{\text {rd }}$ edn. Philadelphia: JB Lippincott 1998:765-78.

[2] Strek P, Reroń E, Maga P, et al. A possible correlation between vertebral artery insufficiency and degenerative changes in the cervical spine. Eur Arch Otorhinolaryngol 1998; 255(9):437-40.

[3] Burns RA. Basilar-vertebral artery insufficiency as a cause of vertigo. Otolaryngol Clin North Am 1973; 6(1):287-300.

[4] Kuhl V, Tettenborn B, Eicke BM, et al. Color-coded duplex ultrasonography of the origin of the vertebral artery: normal values of flow velocities. J Neuroimaging 2000; 10(1):17-21.

[5] Buckenham TM, Wright IA. Ultrasound of the extracranial vertebral artery. $\mathrm{Br}$ J Radiol 2004; 77(913):15-20.

[6] Bull J, el Gammal T, Popham M. A possible genetic factor in cervical spondylosis. Br J Radiol 1969; 42(493):9-16.

[7] BRAIN. Some unsolved problems of cervical spondylosis. Br Med J 1963; 1(5333):771-7.

[8] Teresi LM, Lufkin RB, Reicher MA, et al. Asymptomatic degenerative disk disease and spondylosis of the cervical spine: MR imaging. Radiology 1987; 164(1):83-8.

[9] Bendick PJ, Glover JL. Vertebrobasilar insufficiency: evaluation by quantitative duplex flow measurements. A preliminary report. J Vasc Surg 1987;5(4):594-600.

[10] Touboul PJ, Bousser MG, LaPlane D, et al. Duplex scanning of normal vertebral arteries. Stroke 1986; 17(5):921-3.

[11] Liu MH, Zhou QC, Zhong MY. High frequency color duplex sonography in cervical spondylosis. Hunan Yi Ke Da Xue Xue Bao 2002; 27(1):46-8.

[12] Seidel E, Eicke BM, Tettenborn B, et al. Reference values for vertebral artery flow volume by duplex sonography in young and elderly adults. Stroke 1999; 30(12):2692-6.

[13] Machała W, Gaszyński W, Olszewski J, et al. The effect of degenerative cervical spine lesions and blood flow velocity in vertebrobasilar system in Doppler measurement. Neurol Neurochir Pol 1995; 29(1):17-23. 